\title{
The Advantages of Interactive Whiteboard Technology in the Development of Children's Learning
}

\author{
Haiza Hayati Baharudin ${ }^{1}$, Abdul Halim Masnan², Azizah Zain ${ }^{3}$ \\ ${ }^{1}$ Sultan Idris Education University, 35900 Tanjung Malim, Perak, Malaysia \\ ${ }^{2,3} \mathrm{PhD}$, Early Childhood Education Department, \\ Sultan Idris Education University,35900 Tanjung Malim, Perak, Malaysia
}

Article History: Received: 10 November 2020; Revised: 12 January 2021; Accepted: 27 January 2021;

Published online: 05 April 2021

Abstract: The use of Information and Communication Technology (ICT) in education is expanding with the
development of related studies worldwide. The use of the Interactive Whiteboard (IWB) technology is one of the
most widely used ICT technology equipment in the classroom. In this article I will discuss the advantages of
using IWB in the classroom of early childhood education institutions or preschools which include active
participation of children in learning, developing learning habits, improving achievement in learning and helping
to improve children's literacy skills.

Keywords: Information and Communication Technology, Interactive Whiteboard Technology, Preschools, Childhood Education

\section{Introduction}

The development and influence of information and communication technology (ICT) in education has been encouraging and accepted by most educational institutions. Many researchers agree that ICT technologies such as smartphones, interactive whiteboards and tablets can help improve children's academic achievement. However, its use is limited in schools due to some constraints such as teacher skills and technical support.

The use of the Interactive Whiteboard (IWB) in preschools is ideal as children will be more likely to interact and collaborate with others using this tool. (Sandvik, Smordal\&Osterud, 2012). Children are also quick to learn using this device as it is easy to operate, and moreover children have been exposed to similar technology devices at home. (Couse \& Chen, 2010). According to Estefania, David, Pablo, Cristina, Cristian and Hermelinda (2018) in their study of the impact of interactive devices in early childhood education in Spanish, show that the IWB is capable of capturing children's attention and interest as it is a new tool. This technology can enhance children's motivation when used appropriately by teachers. The use of IWB encourages interaction and collaboration between children as they discuss finding the right answers and helping their friends. It also promotes children's involvement in the learning process where they learn in a highly collaborative environment as they help one another. This interactive technology is best used for children as they learn faster and independently and provide opportunities to explore the use of these tools as well as focus on the learning content presented.

However according to the findings of Estefania and colleagues (2018) there is an issue in the use of this IWB where it is placed in a position that is not appropriate to the height of children. This will make it difficult for them to interact with this equipment more effectively. But it still does not hinder their focus on learning using this technology, especially with the help of teachers. The results of children's learning achievement increased with the use of IWB technology and enabled the teacher to change the perspective of ICT technology in the classroom.

\section{Active Participation in Learning}

Teachers who use IWB in classroom teaching and learning can encourage children's involvement in learning activities. According to Mary Bourbour and Camilla Bjorklund (2014) teachers also agree that the use of IWB can enhance children's involvement in active learning processes. The use of IWB can increase children's confidence to engage in activities, especially at the beginning of the year when they are still new to the school environment. This way teachers will be able to engage children in engaging in communication and learning environments with teachers and other peers. The use of IWB builds an active learning environment and provides opportunities for children to explore using a variety of physical and visual objects (Mary Bourbour\& Camilla Bjorklund, 2014). 
According to Angela Lee and Yen Huai Jen (2015), there is an increase in children's involvement in the use of IWB as a teaching medium by the teachers even though the teacher has not received formal training in its use. This shows that teachers who use IWB as a medium of instruction have been able to attract children to learn especially difficult subjects such as literacy and indirectly improve their level of achievement.

\section{Developing a Child's Learning Attitude}

The use of IWB in learning, especially for subjects that are not well-known or difficult to understand, is seen to change their learning attitude to be more positive and ready to learn. According to Mary Bourbour and Camilla Bjorklund (2014) integrating IWB in preschool learning will strengthen and facilitate the process of learning new ideas for children, helping them think analytically, more motivated and excited to engage actively and teachers teach closer to each child.

Children need to be prepared to learn properly from the first day they attend school. This is because their first perception on the first day of school will influence their later learning habits. These children come from a diverse and varied environment between home and school, so the school environment is a whole new and foreign environment to them. Therefore, teachers need to play a role in creating a fun and stimulating learning environment for children to learn. In addition, teachers need to be more creative in attracting children to actively engage in activities and to eradicate their sense of shame and fear. The use of IWB is seen as the best alternative for children's interest in learning because it's can foster a variety of positive attitudes towards learning such as motivation and focus. This is supported by Athanasios S. Drigas and George Papanastasiou (2014) who stated that the IWB is a very effective tool to provide initiative and facilitate children to understand, remember and think especially for children who are willing to interact directly with this equipment. In addition, the color and movement on the screen they see will increase their concentration on learning.

The interactive functions of IWB technology help children develop positive attitudes to learning, including fun and readiness to learn. Their experience using the IWB itself will impact their enjoyment of learning and their readiness to learn. Children should therefore be given the opportunity to experience their own interaction experiences with the IWB to enhance their learning skills (Yi-fang Luo\&ShuChing Yang, 2016). The positive impact of IWB use on children's learning styles is due to several factors according to ThouqanSaleem and YakoubMasadeh (2016), first; IWB promotes student-centered learning by integrating the use of multimedia as the basis for a broad range of learning activities. The use of IWB also uses children's visuals, hearing and touch senses to build mental images in helping to solve problems related to complex terms and concepts that affect their enjoyment and understanding of learning. It also helps to enhance children's understanding and recall of words used in visual or speech. Second; IWB technology has the potential to increase children's engagement in learning activities with their understanding of complex learning concepts at various levels. The ease of use of the IWB includes that children do not need to copy during learning, they simply keep and print notes with the help of teachers, this will increase their focus on learning without interruption. Third; teaching and learning using the IWB will shape children's learning habits such as enhancing curiosity, promoting communication and interaction as they learn and focus, enhance their imagination, be more interested in physical activity, manipulation skills and motivational words from teachers to improve achievement student. Therefore through the use of IWB children will become active learners and help improve their progress and achievement in their learning.

\section{Improving Children's Achievement in Learning}

Teaching and learning in the classroom using the interactive whiteboard (IWB) appears to have a positive impact on student achievement (KhorHuan Chin \& Noraini Mohamed Noh, 2016). In addition, the implementation of teaching that integrates the use of IWB in the curriculum will be more effective and positively impact on children's achievement and education system. Furthermore, the use of IWB in teaching and learning has a lasting impact on children's memory and transforms their learning style into a positive and stimulating experience. This statement was supported by NibalAbdelkarim and MousaMalkawi (2017) who stated that the use of IWB helps students to achieve better examination and learning outcomes. The application of IWB technology in the classroom creates a positive and engaging environment for children and indirectly stimulates their understanding of learning from all ages (ThouqanSaleem\&YakoubMasadeh, 2016).

\section{Helps Improve Children's Literacy Skills}

Learning literacy skills such as listening, speaking, reading and writing is not easy especially for children in early childhood. It requires more effective and creative teaching techniques from teachers to increase children's mastery of this learning. The use of the old method is still relevant but it needs to be improved with the 
application of IWB technology in line with the development and exposure of children to today's technology. This statement was supported by KhorHuan Chin and NorainiMohemed Noh (2016) who stated that IWB technology not only improves writing skills, but also creates a more enjoyable learning environment, as well as benefits teachers where teaching is more systematic and organized. The integration of the IWB into literacy skills is seen as contributing to the improvement of interaction and communication among children and teachers. According to Mary Bourbour and Camilla Bjorklund (2014), the use of IWB helps teachers share and solve problems with students by encouraging interaction and communication through collaboration. The features of the IWB help keep children interested and engaged in learning especially literacy skills that are more focused on visual and textual forms. Maryam Bourbour and Camilla Bjorklund (2014) also agree that the use of IWB can motivate and maintain children's interest and focus on activities. Although IWB is seen as enhancing children's mastery of learning especially literacy skills, it still depends on the way teachers apply this technology to the extent that it can positively impact children's achievement and social development (Maryam Bourbour\& Camilla Bjorklund, 2014)

\section{Conclusion}

The teaching and learning strategies of teachers in the classroom are very important to ensure that children are able to master the objectives and knowledge that the teacher wants to convey. The use of IWB in teacher teaching strategies enhances children's focus and focus on learning especially at the beginning of the year where they are still engaged in the school environment. Here teachers use the IWB to encourage children to learn and interact in a more stimulating and friendly learning environment while also actively encouraging children's involvement in learning.

The use of IWB can change children's attitudes and ways of learning more positively as learning processes become easier and motivate them. Strategies to foster positive learning habits in children need to be developed on the first day of school as it will influence their future learning habits. If teachers adopt effective learning strategies especially the use of IWB will enhance children's confidence and encourage their active participation in learning activities. Preparing for learning is important for preschoolers to gain new skills and knowledge. Teachers need to think of the best strategies to ensure that children are ready to learn and gain new skills. The use of an interactive IWB can build a positive attitude toward children's learning. In addition, the use of IWB also promotes student-centered learning and active engagement where children will interact with the equipment themselves. They are able to solve specific problems in a fun environment and indirectly enhance their understanding.

Children's achievement can be enhanced through learning using IWB as it creates an effective learning environment and has a positive impact on children. Learning implemented through IWB will have a lasting impact on children and can improve their achievement. Introducing new skills and knowledge to children is a challenge for teachers. Teachers need to use effective strategies to engage children in learning and keep their focus. Learning literacy skills is one of the challenges for teachers to apply to children. The use of IWB can enhance children's literacy skills such as listening, speaking, reading and writing. In addition, the use of IWB can also keep children focused, foster their confidence, increase their motivation and mastery of learning. However, the way teachers present and apply this technology is crucial in ensuring that these strategies are able to achieve their learning objectives.

\section{References}

1. Angela, L. \& Yen, H.J. (2015). Interactive whiteboard into music teaching and Learning : Preschool children as a case study. Procedia-Social \& BehavioralScience, 177, 449-458

2. Couse, L., \& Chen, D. W. (2010). A tablet computer for young children? Exploringits viability for early childhood education. Journal of Research on Technology in Education, 43(1), 75-98. Retrieved from https://bit.ly/2rVAD7m

3. Digital whiteboard tool early literacy instruction. (n.d.). Retrived from https:/www.readingrockets.org/article/digital-whiteboard-tool-early-literacy-instruction

4. Drigas, A.S., \&Papanastasiou, G. (2014). Interactive whiteboard in preschool andPrimary education. iJOE. 10(4)

5. Giannikas, C. N. (2016). The use of interactive whiteboard: Enhancing the nature of teaching young language learner.In S. Papadima_Sophocleous, L. Bradley \&S.Thouseny (Eds.). CALL Communities and Culture - shorts paper from EUROCALL 2016 (pp.160-166)

6. Interactive Whiteboard in Education. (n.d.). Retrieved from edtech-trainingWeebly.com/uploads/1/1/2/7/11275296/interactive whiteboards_pdf 
7. Interactive Whiteboard for $21^{\text {st }}$ Century Smartclassroom Interactive Learning (n.d). Retrieved from israk.my/interactive-whiteboard

H.C., Noraini

Mohamed

Noh.

(2016).

KeberkesananpenggunaanpapanputihInteraktifdalampembelajaranBahasa

Malaysia

dalamkalanganmuridtahun3. JPBU EdisiKhas.

9. Main benefit of interactive whiteboards in the classroom (n.d.). Retrieved from https://www.platinumcopiers.com/aquos-board/7-benefits-of-interactive-whiteboards-in-theclassroom/

10. Martin, E., Roldan-Alvarez, D., Haya, P. A., Fernandez-Gaulles, C., Guzman, C., \&Quitanar, H. (2018). Impact of using interactive devices in Spanish early Childhood education public schools. Journal of Computer Assisted Learning, 1-12

11. Maryam Boubour\& Camilla Bjorklund. (2014). Preschool teacher's reasoning about IWB embedded in Math education in Swedeen preschool. Journal of NordicEarly Childhood education Research. 7, 1-16

12. NibalAbdelkarimMousaMalkawi (2017). The effect of using smart board on the Achievement of tenth grade students in English language and on verbal interaction during teaching in public school. International Research in Education, 5(1)

13. Sandvik, M., Smordal, O., \&Osterud, S. (2012). Exploring iPads in practicioners's repertoires for language learning and literacy practices in kindergarten. NordicJournal of Digital Literacy, 7(3), 204-220. Retrieved from https://bit.ly/21S714B

14. ThouqanSaleem\&YakoubMasadeh.(2016). The effect of interactive whiteboard use on the academic achievement of pupils in English. Researchjournali's Journal of Education, 4(10)

15. Yi-Fang, L., \& Shu, C.Y. (2016). The effect of the interactive functions of whiteboardon elementary students learning. Journal of Education Computing Research. 